\title{
PROPRIEDADES DE ARGAMASSAS COM EVA (ETHYLENE VINYL ACETATE) EM SUBSTITUIÇÃO PARCIAL AO AGREGADO
}

\author{
Mortar properties with EVA (Ethylene Vinyl Acetate) in partial \\ replacement of aggregate
}

\author{
Érica Souza Andrade ${ }^{1}$, Cleidson Carneiro Guimarães ${ }^{2}$
}

Recebido em 08 de março de 2016; recebido para revisão em 18 de maio de 2016; aceito em 28 de outubro de 2016; disponível on-line em 13 de março de 2017.

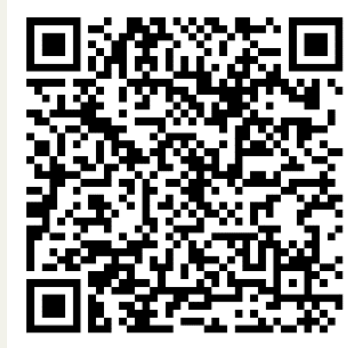

PALAVRAS CHAVE:

Argamassa;

Substituição parcial;

Agregado;

Resíduo de EVA;

Argamassa leve.

\section{KEYWORDS:}

Mortar;

partial replacement;

household;

EVA residue;

Mortar light.

RESUMO: O setor da construção civil apresenta grande potencial para aproveitamento de vários tipos de resíduos industriais. A incorporação dos resíduos, principalmente nas argamassas e concretos, produtos com vasta aplicabilidade no setor, tem se mostrado como uma ótima alternativa na diversificação das matérias-primas e para a economia de recursos naturais. Esse trabalho avaliou as propriedades das argamassas, no estado fresco e endurecido, produzidas com substituição parcial da areia por resíduo de EVA (Ethylene Vinyl Acetate). Para isso, foram preparadas argamassas com teores de substituição do agregado $0 \%$ (referência), 5\%, 10\% e 15\%, em massa. A relação água/cimento, para cada traço, foi determinada empiricamente e mantida constante para as argamassas com substituição. Os resultados apontam que as argamassas produzidas com agregado de EVA apresentam menor absorção de água e também um decréscimo da resistência mecânica. Desta forma, a produção de argamassas utilizando EVA em substituição ao agregado natural é viável, todavia é necessário avaliar os parâmetros mínimos de aplicação para cada finalidade. Dessa forma, o trabalho apresenta contribuição ao servir de suporte a gestores de empresas de argamassas ou gestores de obra a tomarem decisões acerca da inserção do resíduo de EVA na produção de argamassa.

ABSTRACT: The construction sector has great potential for use of various types of industrial waste. The incorporation of waste, especially in mortar and concrete products with wide applicability in the industry, has proven to be a great alternative for diversification of raw materials and the economy of natural resources. This study evaluated the properties of mortars in fresh and hardened state, made with partial replacement of sand by waste EVA (Ethylene Vinyl Acetate). For this, mortars were prepared with substitution aggregate content 0\%(reference), 5\%, 10\% and 15\% by weight. The water / cement ratio for each trace has been empirically determined and maintained constant for the mortars with replacement. The results show that the mortars produced with EVA aggregate have lower water absorption and also a decrease in the mechanical strength. Thus, the production of mortar using EVA instead of natural aggregate is feasible, however, it is necessary to evaluate the minimum parameters for each application purpose. Thus, the work presents contribution to provide support for the mortar company managers or project managers make decisions about the insertion of EVA residue in the production of mortar.

* Contato com os autores:

${ }^{1}$ e-mail: erica.ufrb@gmail.com ( E.S. ANDRADE)

Bacharela em Ciências Exatas e Tecnológicas, Graduanda em Engenharia Civil pela Universidade Federal do Recôncavo da Bahia (UFRB).

2e-mail: cleidsonguimaraes@ufrb.edu.br (C. C. GUIMARÃES )

Engenheiro Civil, Mestre em Engenharia Civil e Ambiental, Professor do Centro de Ciências Exatas e Tecnológicas (CETEC) na Universidade Federal do Recôncavo da Bahia (UFRB). 


\section{INTRODUÇÃO}

O processo de industrialização e urbanização associado ao desenvolvimento tecnológico além de trazer grandes benefícios para a sociedade, trouxe também malefícios ao meio ambiente, por exemplo, a crescente geração de resíduos sólidos e o gerenciamento, muitas vezes incorreto dos mesmos (GARLET, 1998; ROCHA, 2008 e MARQUES et al., 2012).

A produção de resíduos industriais se constitui como uma das principais formas de degradação do meio ambiente (BALDIN; ORTH; ZANOTELLI, 2014). Atualmente, devido à rigorosa fiscalização dos órgãos de controle ambiental, muitas empresas têm buscado alternativas ecotécnicas e econômicas para resolver os problemas de impactos ambientais (SOARES ${ }^{1}, 2007$ apud SANTIAGO, 2008).

$\mathrm{Na}$ indústria calçadista não é diferente. Sendo um dos maiores segmentos industriais do Brasil, com mais de oito mil empresas, no cenário atual, impulsionadas pelas competições de mercado e pela moda, elevaram a sua produtividade, cerca de 800 milhões em 2015 e cerca de 11 milhões de pares de calçados no mês de janeiro de 2016, onde o Estado da Bahia é o 6으 maior produtor de calçados (ABICALÇADOS, 2016), e, consequentemente, a geração de resíduos sólidos, em especial dos resíduos de Etileno Acetato de Vinila (EVA).

$O$ resíduo de EVA é um polímero termofixo o que impossibilita sua reintegração no processo de produção de placas de palmilhas e solados. Além disso, o resíduo de EVA possui baixa densidade e não é um produto biodegradável, portanto, demandam área, cada vez maiores, para suportar os grandes volumes gerados. Diante deste contexto, faz-se necessário a busca de soluções

${ }^{1}$ BRINGEL, R. M.; SOARES, S. A.; SOARES, J. B. Propriedades químicas e reológicas de asfalto modificado por copolímero EVA. In.: $3^{\circ}$ Congresso Brasileiro de P\&D em Petróleo e Gás. Instituto Brasileiro de Petróleo e Gás - IBP - Salvador, 2005. 6 p. Disponível em:

http://www.portalabpg.org.br/PDPetro/3/trabalhos/IBP0 605_05.pdf. alternativas para a utilização deste resíduo (GARLET, 1998 e DEBAPRIYA; SUKUMAR; ADHIKARI ${ }^{2}, 1990$ apud MARQUES et al., 2012).

Segundo Polari Filho (2005), a indústria da construção é o setor da economia com maior potencial para aproveitamento de vários tipos de resíduos industriais. Entre os resíduos possíveis de serem inseridos na construção, apresentam-se os resíduos da indústria calçadista que podem ser incorporados em produtos cerâmicos e cimentícios, substituindo os agregados naturais, promovendo o desenvolvimento sustentável, baseando-se na conservação e preservação ambiental.

Os agregados naturais empregados na construção civil são abundantes na natureza. Porém, fatores geológicos e restrições econômicas e ambientais tornam inviável a extração dos agregados de lugares distantes dos grandes centros (LA SEMA, REZENDE, 2009). O esgotamento das jazidas de areias naturais próximas aos grandes centros de consumo, a contaminação das fontes de material pela poluição e as políticas de proteção ambiental fazem com que a obtenção de agregados miúdos para emprego na construção civil, particularmente na produção de compósitos cimentícios convencionais, seja impulsionada na direção de novas opções. Desta forma, novas alternativas estão sendo estudadas, dentre elas o emprego de areias artificiais ou a substituição de agregados por resíduos (LODI, 2006).

Reutilizar e reciclar os resíduos industriais estão entre as principais alternativas na busca pelo desenvolvimento sustentável. $\mathrm{E}$ a incorporação das aparas das indústrias calçadistas em produtos para a construção civil mostra-se como uma alternativa para diversificar a oferta de matérias-primas e para

\footnotetext{
${ }^{2}$ DEBAPRIYA, D.; SUKUMAR, M.; ADHIKARI, B. Reclaiming of rubber by a Renewable Resource Material (RRM). II. Comparative Evaluation of Reclaiming Process of NR Vulcanizate by RRM and diallyl disulfide. Journal of Applied Polymer Science, v.73, p.2951, 1999.
} 
a economia de recursos naturais (MENEZES ${ }^{3}$ et al., 2002a, 2002b, 2005 apud ROCHA et al., 2008).

A utilização de resíduos de EVA (Etileno Acetato de Vinila), resultado da produção de sandálias, na construção civil tem sido objetivo de pesquisas nos últimos anos. Sabe-se que tais resíduos têm grande potencial para serem empregados como agregados leves, em substituição aos agregados naturais, na elaboração de compósitos cimentícios alternativos. (MELO; LIMA FILHO, 2009).

Garlet (1998), investigou a possibilidade de utilizar concreto com EVA, avaliando as propriedades mecânicas do mesmo com diferentes consumos de cimento, utilizando traços 1:3; 1:5 e 1:7 (cimento:agregado, em massa) e teores de 60\%; 70\%; 80\%; $90 \%$ e $100 \%$ de agregado de EVA em relação ao volume de agregado, e concluiu que há um decréscimo da resistência à compressão e à tração por compressão diametral acompanhada da diminuição do consumo de cimento e da elevação dos teores de EVA. Já a absorção de água aumenta consideravelmente com o aumento do teor de agregado de EVA na mistura. O mesmo autor aponta que devido a baixa resistência à compressão, onde a resistência mais elevada foi de 3,4 $\mathrm{MPa}$, obtida para a mistura com traço 1:3 com $60 \%$ de EVA, os concretos com resíduos de EVA somente podem ser empregados em funções não estruturais, tais como: isolamento térmico e acústico, enchimento de lajes e contrapisos e em elementos pré-moldados não portantes.

Polari Filho (2005), por meio de suas pesquisas com blocos de concreto com resíduos EVA, utilizando na mistura para confecção dos blocos concretos com traço 1:3 (cimento:agregado, em massa) com teores de 60\%; $70 \%$ e $80 \%$ de agregado de EVA em substituição ao agregado

\footnotetext{
${ }^{3}$ MENEZES, R. R., NEVES, G. A., FERREIRA, H. C. O estado da arte sobre o uso de resíduos como matérias-primas cerâmicas alternativas. Revista Brasileira de Engenharia Agrícola e Ambiental, v. 6, n. 2, p. 303-317, 2002a.

MENEZES, R. R. et al. Recycling of granite industry waste from the northeast region of Brazil. Environmental Management and Health, v. 13, p. 134-142, 2002 b.

MENEZES, R. R. et al. Use of granite sawing wastes in the production of ceramic bricks and tiles. Journal of the European Ceramic Society, v. 25, p. 1149-1163, 2005.
}

natural (areia) e também concreto com traço 1:5 (cimento:agregado) com 60\% de agregado de EVA em substituição a areia, concluiu que devido ao fato de as indústrias calçadista produzirem diferentes tipos de calçados há uma grande variabilidade dos resíduos, os quais apresentaram uma variação em sua massa unitária em estado solto de $100 \mathrm{~kg} / \mathrm{m}^{3}$ a $180 \mathrm{~kg} / \mathrm{m}^{3}$. Com a produção dos blocos e dos painéis de EVA, ele constatou que a resistência à compressão dos mesmos é inversamente proporcional ao teor de incorporação do agregado EVA.

Andrade e Medeiros (2012) estudaram a viabilidade de utilizar o resíduo de EVA como agregado leve e como isolante acústico e concluíram que este resíduo pode ser aplicável como agregado em microconcreto ${ }^{4}$ leve como enchimento de laje como isolante acústico. Podendo também o microconcreto, desenvolvido em sua pesquisa, ser uma solução viável para qualquer tipo de edificação de concreto armado em relação ao isolamento acústico.

A fase agregado, nas argamassas, é a principal responsável pela massa unitária, pelo módulo de elasticidade e pela estabilidade dimensional (METHA e MONTEIRO, 1994). A distribuição contínua dos agregados, assim como a sua morfologia, pode maximizar o empacotamento das partículas nas argamassas, fazendo com que os espaços vazios, deixados pelas partículas maiores, sejam preenchidos com partículas de tamanho adequado (menor) e assim sucessivamente (CARDOSO, 2009). O autor ressalta também que o elevado empacotamento das partículas diminui a porosidade da argamassa, aumenta a resistência à compressão e diminui a absorção, geralmente. Desta forma, pode-se obter um material com menor índice de vazios, melhorando assim suas propriedades físicas e mecânicas.

Além da utilização na produção de concretos e blocos de concretos, os resíduos de EVA podem ser inseridos na construção civil também através das argamassas, produtos presentes em diversas fases de uma construção, e

\footnotetext{
${ }^{4}$ Classifica-se como microconcreto, todo concreto que possui em sua composição agregados com dimensões máxima de $9,5 \mathrm{~mm}$.
} 
que se constituem um dos materiais mais empregados na construção civil, desempenhando diversas finalidades e aplicações, sendo seus principais usos no assentamento de alvenarias e nas etapas de revestimento de paredes e tetos (CARASEK, 2010).

A NBR 13281 (ABNT, 2005) define argamassas como "mistura homogênea de agregados miúdos, aglomerantes inorgânicos e água, contendo ou não aditivos, com propriedades de aderência e endurecimento". Também define as tipologias das argamassas, sendo estas de assentamento de alvenaria (vedação e estrutural), encunhamento e, argamassas de revestimento (interno e externo) de paredes e tetos, argamassa de uso geral e de reboco e, argamassas decorativas de camada fina ou monocamada.

Este trabalho objetiva investigar as propriedades das argamassas com resíduos de EVA (Ethylene Vinyl Acetate) em substituição parcial ao agregado. Visando dar uma destinação ambientalmente segura aos resíduos industriais quanto ao desenvolvimento de produtos da construção com características que permitam sua aceitação no mercado. Ao mesmo tempo, busca também, reduzir o consumo de agregados naturais e consequentemente os danos causados, ao meio ambiente, por sua extração.

\section{METODOLOGIA}

A avaliação da viabilidade técnica do uso de resíduos de EVA em argamassas, com substituição parcial do agregado, consistiu-se em produzir dois traços, um deles rico em cimento Portland (1:3) e outro com baixo teor desse aglomerante hidráulico (1:6). A adoção visa avaliar situações onde o emprego de argamassa não requer elevadas resistências, tais como as argamassas de enchimento de lajes e contrapisos.

Foram moldados corpos de prova cilíndricos de argamassa com traços 1:3 e 1:6 (em massa) contendo apenas cimento, areia e água, denominados por referência. Em seguida, em cada traço, o agregado foi substituído pelo resíduo EVA em percentuais 5\%, $10 \%$ e 15\%, em massa de agregado. A Tabela 1 apresenta os teores, em massa, de cada um dos componentes das argamassas desse programa experimental. A relação água/cimento $(\mathrm{a} / \mathrm{c})$ foi obtida por meio de observação empírica, acrescentando água até obtenção da trabalhabilidade adequada para moldagem dos corpos de prova.

\begin{tabular}{cccccc}
\hline \multirow{2}{*}{ TABELA 1: Consumo de materiais, em grama, por traço unitário. } \\
Materiais & Traço & Ref. & $\mathbf{5 \%}$ & $\mathbf{1 0 \%}$ & $\mathbf{1 5 \%}$ \\
\hline \multirow{2}{*}{ Cimento } & $1: 3$ & 611,11 & 611,11 & 611,11 & 611,11 \\
& $1: 6$ & 360,42 & 360,42 & 360,42 & 360,42 \\
\hline \multirow{2}{*}{ Areia } & $1: 3$ & 1833,33 & 1741,67 & 1650,00 & 1558,33 \\
& $1: 6$ & 2162,52 & 2054,39 & 1946,26 & 1838,14 \\
\hline \multirow{2}{*}{ EVA } & $1: 3$ & 0,00 & 91,67 & 183,33 & 275,00 \\
& $1: 6$ & 0,00 & 108,13 & 216,25 & 324,38 \\
\hline \multirow{2}{*}{ a/c } & $1: 3$ & 0,50 & 0,50 & 0,50 & 0,50 \\
& $1: 6$ & 0,63 & 0,63 & 0,63 & 0,63 \\
\hline
\end{tabular}




\section{MATERIAIS E PROGRAMA EXPERIMENTAL}

A parte experimental desta pesquisa consistiu-se na confeç̧ão dos corpos de prova cilíndricos $(50 \mathrm{~mm} \times 100 \mathrm{~mm})$ os quais ficaram em cura por um dia, no molde, ao ambiente e 27 dias em água saturada de cal. Os ensaios foram realizados no Laboratório de Materiais de Construção II, da Universidade Federal do Recôncavo da Bahia (UFRB).

\subsection{Materiais}

\subsubsection{Cimento}

$\mathrm{Na}$ mistura das argamassas, utilizou-se cimento Portland composto CP V - ARI. Empregouse esse tipo de cimento porque não possui adições pozolânicas e o teor de inertes é o mais baixo.

\section{A Tabela 2 apresenta a composição} química e os índices físicos do cimento Portland. A massa específica ${ }^{5}$ do cimento é de $3,08 \mathrm{~g} / \mathrm{ml}$.

\subsubsection{Areia}

$\mathrm{O}$ agregado utilizado foi areia natural de origem quartzosa, facilmente encontrada na cidade de Cruz das Almas - BA e, utilizada toda fração passante na malha $4,8 \mathrm{~mm}$. A Tabela 3 apresenta as propriedades físicas desse agregado.

TABELA 2: Composição química e índices físicos do CP V ARI.

\begin{tabular}{ccccc}
\hline \multicolumn{2}{c}{ Composição Química (\%) } & \multicolumn{2}{c}{ Finura \% } & Blaine \\
\hline $\mathrm{Fe}_{2} \mathrm{O}_{3}$ & 3,59 & $\# 200$ & $\# 325$ & $\mathrm{~cm}^{2} / \mathrm{g}$ \\
$\mathrm{CaO}$ & 62,1 & 0,15 & 2,9 & 4.330 \\
$\mathrm{~K}_{2} \mathrm{O}$ & 0,54 & & & \\
$\mathrm{SiO}_{2}$ & 20,54 & & & \\
$\mathrm{SO}_{3}$ & 3,46 & & & \\
$\mathrm{Al}_{2} \mathrm{O}_{3}$ & 3,8 & & \\
$\mathrm{MgO}_{\mathrm{C} 3 \mathrm{~S}}$ & 2,56 & & \\
$\mathrm{CaOL}$ & 56,11 & & \\
$\mathrm{P.F.}$ & 1,56 & & \\
\hline
\end{tabular}

FONTE: MIZU (2015).

\begin{tabular}{ccc}
\hline \multicolumn{4}{c}{ TABELA 3: Características físicas da areia. } \\
\hline \multicolumn{3}{c}{ Propriedades avaliadas } \\
\hline Abertura da peneira (mm) & \% Retido & $\begin{array}{c}\text { \% Retido } \\
\text { Acumulado }\end{array}$ \\
\hline $\mathbf{4 , 8}$ & 0 & 0 \\
$\mathbf{2 , 4}$ & 5,3 & 5,3 \\
$\mathbf{1 , 2}$ & 9,7 & 15,0 \\
$\mathbf{0 , 6}$ & 44,2 & 59,2 \\
$\mathbf{0 , 3}$ & 21,2 & 80,4 \\
$\mathbf{0 , 1 5}$ & 10,8 & 91,2 \\
Menor que 0,15 & 8,8 & 100 \\
\hline Dimensão máxima característica (mm) - NBR NM & 2,4 \\
248 (ABNT, 2003) & & 2,51 \\
\hline Módulo de finura - NBR NM 248 (ABNT, 2003) & 2,60 \\
\hline Massa específica (g/cm ${ }^{3}$ ) - NBR NM 52 (ABNT, & \\
2009) & & \\
\hline
\end{tabular}

FONTE: Autor (2016)

\footnotetext{
${ }^{5}$ Ensaio realizado conforme a NBR NM 23 (2000).
} 
A Figura 1 apresenta a curva granulométrica da areia utilizada, assim como os limites estabelecidos pela norma NBR 7211 (ABNT, 2009), trata-se de uma areia lavada cuja maior concentração dos grãos encontra-se na fração média. Observa-se a ausência de finos e baixo teor de grãos da fração grossa.

\subsection{3 Água}

Nas misturas das argamassas foi utilizada água potável da rede de abastecimento da Universidade Federal do Recôncavo da Bahia. Não foram realizados ensaios de verificação de teores de cloretos ou sulfatos.

\subsubsection{EVA}

O EVA é um polímero que possui baixa massa específica e tem boas características acústicas e térmicas, em condições normais ele é estável e inerte, não suscetível a fungos. Essas características evidenciam a grande potencialidade dos resíduos de EVA para uso como agregado sintético na elaboração de compósitos cimentícios (GARLET, 1998).

O resíduo de EVA utilizado nesta pesquisa tem massa específica $0,12 \mathrm{~g} / \mathrm{cm}^{3}$, sendo, portando menos denso do que os agregados convencionais. Daí, pode-se, dependendo do teor de substituição do agregado miúdo por EVA, classificar a argamassa produzida em argamassa leve.

O resíduo de EVA foi fornecido, triturado, pela Empresa Dass Calçados, localizada no município de Santo Estevão, no Estado da Bahia. Inicialmente foi realizado um peneiramento prévio, empregando a peneira de malha $4,80 \mathrm{~mm}$, pois diversos grãos apresentavam diâmetro maior do que $4,8 \mathrm{~mm}$. A parte retida foi levada ao moinho de facas por um período de 15 segundos e posteriormente passado na peneira $4,8 \mathrm{~mm}$. 0 resíduo utilizado foi caracterizado granulometricamente conforme a NBR NM 248 (ABNT, 2003) e a curva granulométrica é apresentada na Figura 2.

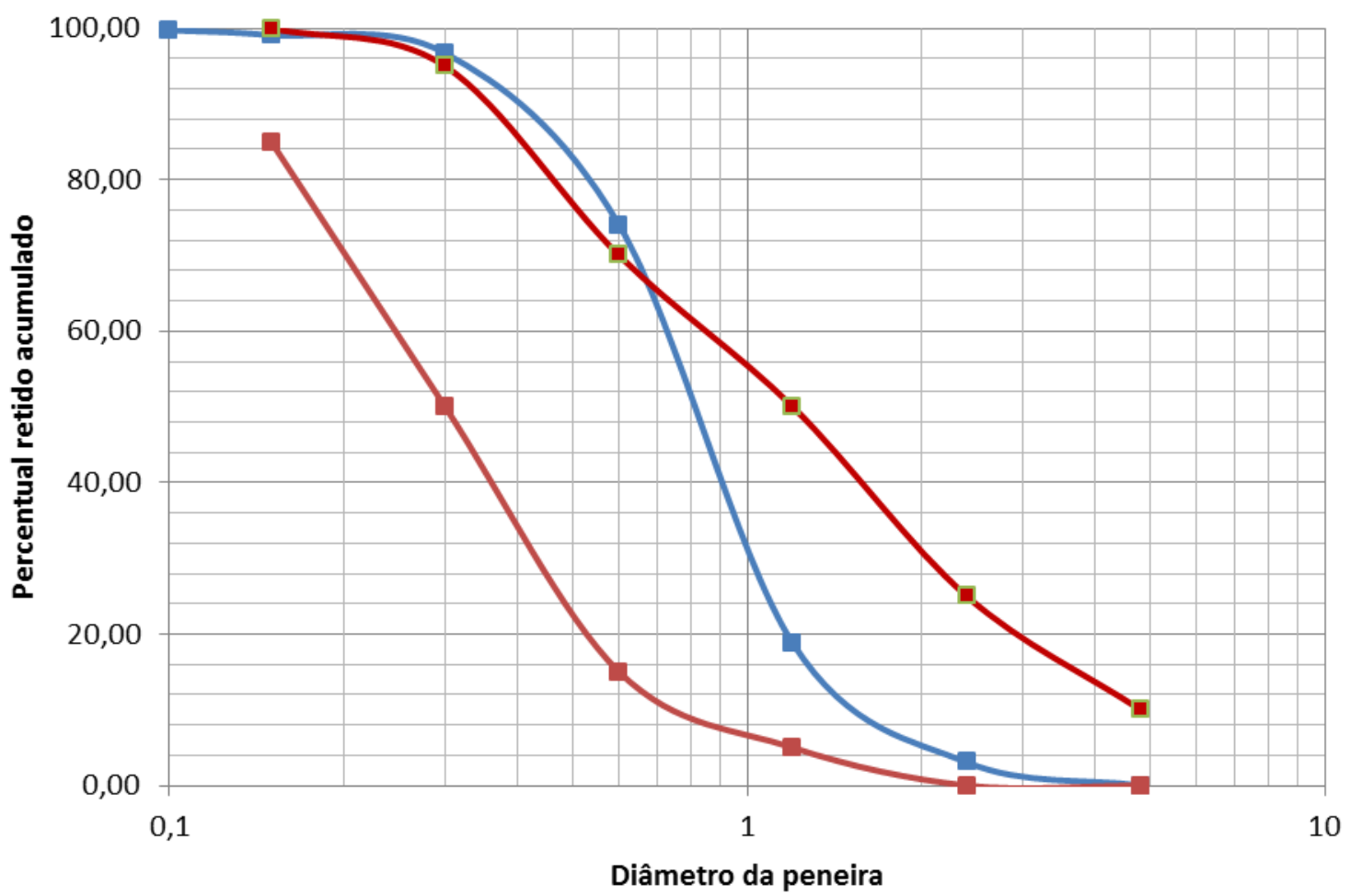

FIGURA 1: Curva granulométrica da areia natural (em azul), apresentando os limites das zonas utilizáveis (em vermelho) inferior e superior conforme a NBR 7211 (ABNT, 1993).

FONTE: AUTOR (2016). 


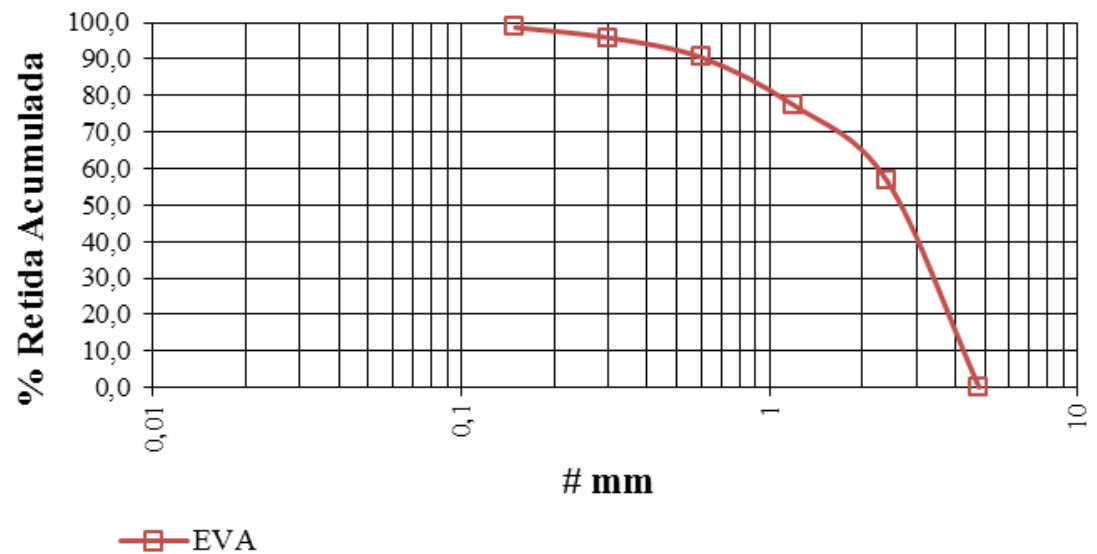

FIGURA 2: Curva granulométrica do agregado de EVA. FONTE: AUTOR (2016).

Comparando a Curva granulométrica do EVA com a do agregado (Figura 1) e analisando a Figura 3, observa-se uma complementaridade de grãos, embora nenhum dos agregados apresente a fração finos que torna a granulometria contínua, como mostrado na Figura 4.

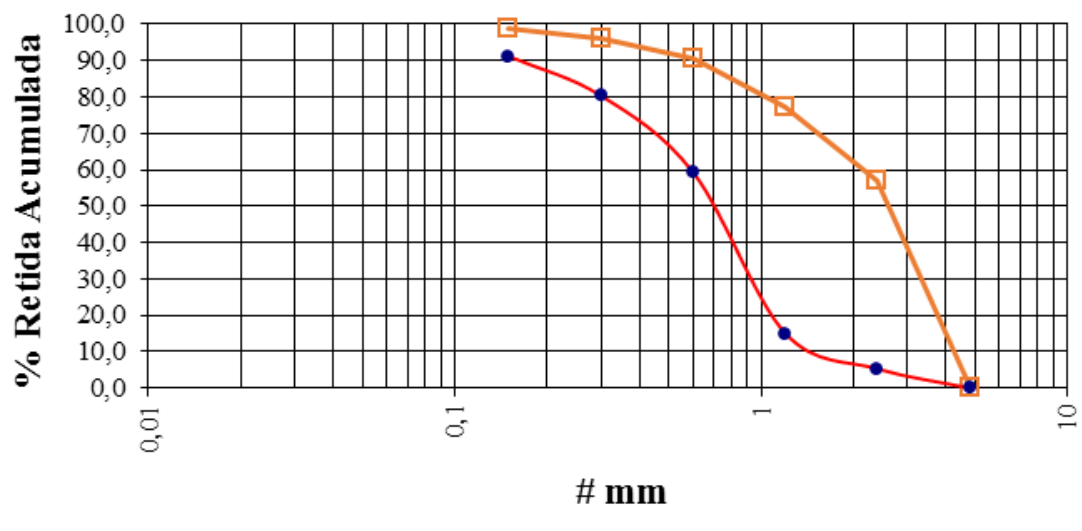

$$
\square \text { EVA } \longrightarrow \text { Areia }
$$

FIGURA 3: Curva granulométrica do agregado de EVA FONTE: AUTOR (2016).

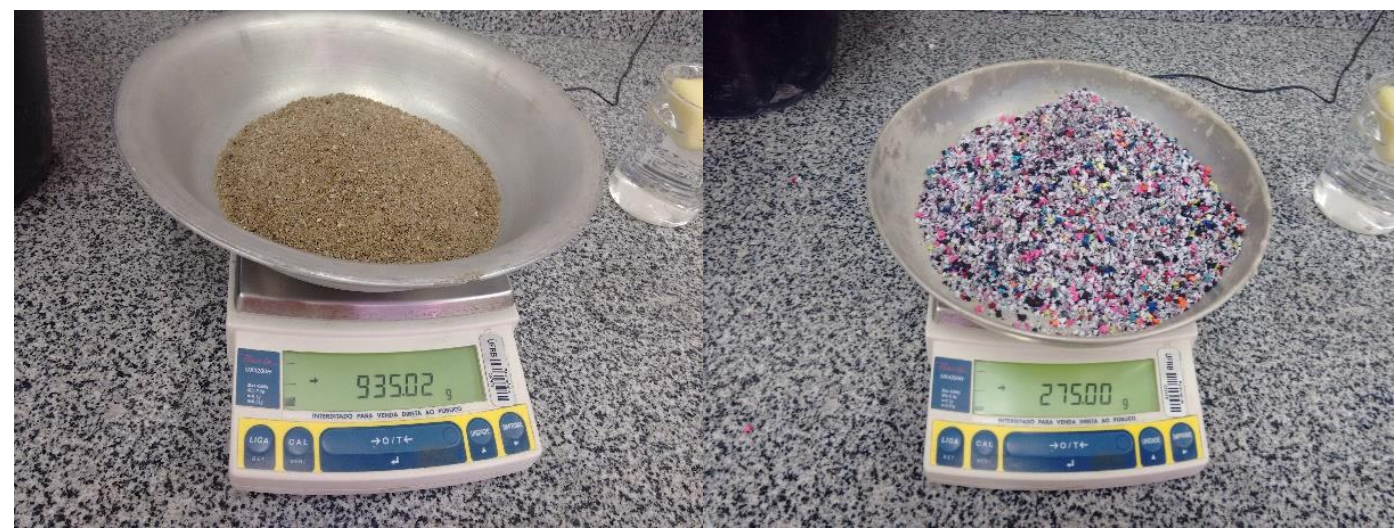

FIGURA 4: Agregado natural (à esquerda) e o resíduo do agregado de EVA (à direita). FONTE: AUTOR (2016). 


\subsection{MÉTODOS}

Para avaliar as propriedades no estado fresco e endurecido, foram preparadas misturas de argamassa de referência com traço igual a 1:3 (cimento/agregado) e relação a/c de 0,5 e, com traço 1:6 (cimento/agregado) e relação a/c de 0,63 . A relação a/c foi obtida empiricamente, ou seja, foi inserida água até obter a trabalhabilidade necessária à moldagem dos corpos de prova. Para as argamassas com o resíduo, foram empregadas as mesmas relações a/c da mistura de referência, naquele traço. A mistura foi realizada empregando a metodologia sugerida pela NBR 7215 (ABNT, 1996). A Tabela 4 apresenta um resumo dos códigos adotados nesse trabalho, tais quais os teores de substituição do agregado miúdo por EVA.

\begin{tabular}{lccc}
\hline \multicolumn{4}{c}{ TABELA 4: Argamassas produzidas } \\
no experimento. \\
\hline Amostras & Traço & Teor de EVA & a/c \\
\hline R 1:3 & $1: 3$ & $0 \%$ & 0,50 \\
EVA 1:3 5\% & $1: 3$ & $5 \%$ & 0,50 \\
EVA 1:3 10\% & $1: 3$ & $10 \%$ & 0,50 \\
EVA 1:3 15\% & $1: 3$ & $15 \%$ & 0,50 \\
\hline R 1:6 & $1: 6$ & $0 \%$ & 0,63 \\
EVA 1:6 5\% & $1: 6$ & $5 \%$ & 0,63 \\
EVA 1:6 10\% & $1: 6$ & $10 \%$ & 0,63 \\
EVA 1:6 15\% & $1: 6$ & $15 \%$ & 0,63 \\
\hline
\end{tabular}

Para caracterizar as argamassas foram realizados os ensaios no estado fresco e endurecido. Como a propriedade de massa é importante no aspecto peso próprio e trabalhabilidade, foi realizado, no estado fresco, a densidade de massa, conforme a norma NBR 13278 (ABNT, 2005). No estado endurecido, foram realizados os ensaios de determinação da resistência à compressão axial nas idades $7,14 \mathrm{e}$ 28 dias, com 6 (seis) exemplares de corpos de prova para cada idade conforme NBR 7215 (ABNT, 1996). Também foram realizados os ensaios de absorção de água por imersão, NBR 9778 (ABNT, 2005), e absorção de água por capilaridade, conforme a NBR 9779 (ABNT, 2012), aos 28 dias, com 6 (seis) corpos de prova para cada ensaio.

\section{APRESENTAÇÃO E ANÁLISE DOS RESULTADOS}

\subsection{ESTADO FRESCO}

\subsubsection{Densidade de massa}

A diminuição da densidade, geralmente, é uma propriedade que torna as argamassas mais trabalháveis em longo prazo, pois diminui os esforços realizados pelos operários na aplicação, promovendo, consequentemente, uma maior produtividade ao final da jornada de trabalho (CARASEK, 2010).

As Tabelas 5 e 6 apresentam a densidade de massa das argamassas no estado fresco.

\begin{tabular}{rccc}
$\begin{array}{r}\text { TABELA 5: Densidade de massa das argamassas } \\
\text { com traço 1:3. }\end{array}$ \\
\hline \multicolumn{4}{c}{$\begin{array}{c}\text { Densidade de massa } \\
\text { (g/cm }{ }^{3} \text { ) }\end{array}$} \\
\hline Amostra & Média & DP & CV\% \\
\hline R 1:3 & 2,29 & 0,10 & 5 \\
EVA 1:3 5\% & 2,08 & 0,05 & 2 \\
EVA 1:3 10\% & 1,79 & 0,08 & 5 \\
EVA 1:3 15\% & 1,57 & 0,17 & 11 \\
\hline \multicolumn{3}{c}{ FONTE: Autor (2016). }
\end{tabular}

Observa-se na, Tabela 6, que houve uma diminuição da densidade de massa das argamassas com substituição parcial do agregado por EVA em relação à argamassa de referência. Essa redução foi de $9 \%, 22 \%$ e $31 \%$ para as substituições de $5 \%$, $10 \%$ e $15 \%$, respectivamente. Esse comportamento era esperado, já que a densidade de uma mistura de materiais depende da densidade dos seus componentes. Como EVA tem uma densidade média $\left(0,11 \mathrm{~g} / \mathrm{cm}^{3}\right)$ menor do que a da areia $(2,60$ $\left.\mathrm{g} / \mathrm{cm}^{3}\right)$, logo, a substituição promove uma redução de densidade da mistura.

\section{TABELA 6: Densidade de massa das argamassas com traço 1:6}

\begin{tabular}{cccc} 
& \multicolumn{3}{c}{ Densidade de massa $\left(\mathrm{g} / \mathrm{cm}^{\mathbf{3}}\right)$} \\
\hline Amostra & Média & DP & DV \\
\hline R 1:6 & 2,03 & 0,11 & 5 \\
EVA 1:6 5\% & 1,75 & 0,16 & 9 \\
EVA 1:6 10\% & 1,54 & 0,15 & 10 \\
EVA 1:6 15\% & 1,37 & 0,11 & 8 \\
\hline & \multicolumn{3}{c}{ FONTE: Autor (2016). }
\end{tabular}


Na Tabela 6 é possível observar uma diminuição de cerca $13 \%$ da densidade de massa da argamassa com substituição de $5 \%$ do agregado por EVA em relação a argamassa de referência e uma diminuição de aproximadamente $24 \%$ e $32 \%$ da densidade nas argamassas com substituição de $10 \%$ e $15 \%$ do agregado na mistura. De forma similar a discussão anterior, a densidade da argamassa diminui com o aumento do teor de substituição de EVA.

Nota-se também que as densidades são maiores para as argamassas com traço 1:3, estas argamassas possuem mais aglomerante, massa específica $3,08 \mathrm{~g} / \mathrm{cm}^{3}$, que as argamassas com traço 1:6. Desta forma, os vazios deixados pelos agregados nas misturas 1:3, são preenchidos pelo aglomerante de forma mais efetiva do que as misturas com traço 1:6, melhorando o empacotamento da mistura, tornando-a mais densa e com menos espaços vazios. Além disso, a relação $a / c$ do traço $1 / 6(0,63)$ é maior do que no traço $1 / 3(0,5)$. Isso significa que no traço $1 / 6$ há mais água disponível ao fenômeno de evaporação e, consequentemente, maior a porosidade originada por esse fenômeno no traço $1 / 6$.

Observando a Figura 5, nota-se a tendência de diminuição da densidade da argamassa com $O$ aumento do teor de substituição do agregado miúdo por EVA. Essa diminuição é favorável ao emprego do EVA em argamassa de preenchimento de contrapiso ou proteção de mantas de impermeabilização. Isso porque, geralmente, quanto menor a densidade da argamassa, menor a propagação de calor e som pelo revestimento. Andrade e Medeiros (2012) apontaram a contribuição desse resíduo na melhoria do conforto acústico de forma que o emprego do resíduo em argamassa poderá promover maior o conforto interno a alvenaria. Aliado a isso, destaca-se que O EVA é um bom isolante térmico. Além disso, o emprego de EVA em argamassa pode aumentar a produtividade do trabalhador (por que reduz o consumo de energia na aplicação) e diminui o peso próprio do elemento construtivo, reduzindo a sobrecarga da estrutura.

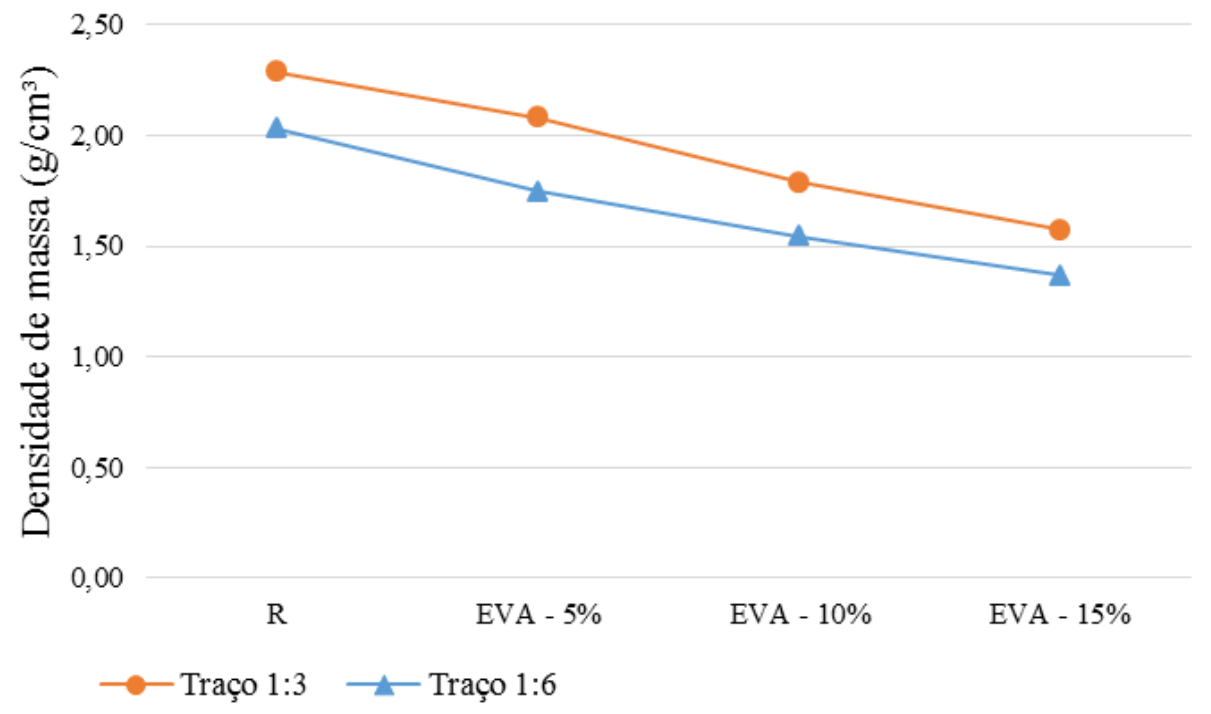

FIGURA 5: Densidade de massas das argamassas. FONTE: Autor (2016) 


\subsection{ESTADO ENDURECIDO}

\subsubsection{Resistência à compressão}

Para Dubaj (2000) a resistência à compressão é a propriedade que melhor representa o desempenho mecânico da argamassa.

A resistência à compressão foi determinada em corpos de prova ensaiados a 7, 14 e 28 dias com base na norma NBR 7215 (ABNT, 1996).

As Tabelas 7 e 8 apesentam os valores da média das resistências à compressão para cada idade ensaiada. Além disso, estão presentes o desvio padrão (DP) e o coeficiente de variação (CV).

De acordo com os resultados apresentados na Tabela 7, nota-se que houve uma diminuição da resistência à compressão axial das argamassas com o aumento do percentual de EVA na mistura, aos 7, 14 e 28 dias. Para os traços $1: 3$, aos 28 dias, os corpos de prova com $5 \%$ de EVA reduziram $34 \%$, em relação à argamassa de referência. Para o teor de $10 \%$, a redução foi de $57 \%$. Com $15 \%$ de EVA, a redução chegou a $71 \%$. Esse comportamento era esperado, pois a resistência à compressão do compósito formado depende da resistência dos grãos que constituem a argamassa $^{6}$, além do empacotamento dessas partículas, conforme destaca Cardoso (2009). O EVA tem uma resistência à compressão menor do que a areia 7 . Dessa forma, a inserção de um material menos resistente, na matriz cimentícia, tende a diminuir a resistência do compósito.

TABELA 7: Resistência à compressão (MPa) aos 7, 14 e 28 dias, das argamassas com traço 1:3.

Resistência à compressão (MPa) aos 7 dias

\begin{tabular}{lccc}
\hline \multicolumn{1}{c}{ Traço } & Resistência Média & DP & CV\% \\
\hline R 1:3 & 32,7 & 1,12 & 3 \\
EVA 1:3 5\% & 19,9 & 1,55 & 8 \\
EVA 1:3 10\% & 15,5 & 0,46 & 3 \\
EVA 1:3 15\% & 10,5 & 0,31 & 3 \\
\hline \multicolumn{4}{c}{ Traço } \\
\multicolumn{4}{c}{ Resistência à compressão (MPa) aos 14 dias } \\
\hline R 1:3 & Resistência Média & DP \\
EVA 1:3 5\% & 36,2 & 1,01 & CV\% \\
EVA 1:3 10\% & 20,1 & 0,60 & 3 \\
EVA 1:3 15\% & 16,0 & 0,10 & 3 \\
\hline
\end{tabular}

Resistência à compressão (MPa) aos 28 dias

\begin{tabular}{lccc}
\hline \multicolumn{1}{c}{ Traço } & Resistência Média & DP & CV\% \\
\hline R 1:3 & 38,8 & 0,75 & 2 \\
EVA 1:3 5\% & 25,6 & 1,14 & 4 \\
EVA 1:3 10\% & 16,5 & 0,70 & 4 \\
EVA 1:3 15\% & 11,2 & 0,18 & 2 \\
\hline & & & FONTE: Autor (2016)
\end{tabular}

\footnotetext{
${ }^{6}$ Adotou o entendimento de todos os constituintes da argamassa como sendo granulométrica, inclusive os produtos da hidratação.

${ }^{7}$ Não foram realizados ensaios de compressão dos grãos de areia ou do EVA. Todavia, esses ensaios tornam-se desnecessários com a simples percepção manual dos dois materiais. Pois o EVA é um plástico (termofixo), enquanto a areia é um material rígido.
} 
Analisando os resultados, Figura 6, constata-se que há um ganho de resistência das argamassas à medida que o tempo passa, esse fenômeno ocorre em função do aumento do teor de silicato de cálcio hidratado (C-S-H) produzido ao longo do tempo pela reação de hidratação do cimento Portland (METHA e MONTEIRO, 1994). Observa-se que a variação da resistência à compressão (entre 7 e 28 dias) é maior tanto menor for o teor de EVA. Provavelmente porque tanto maior o teor de EVA, menor o teor de água livre para reagir, na hidratação do cimento Portland. Pois, há uma tendência de atração eletrostática entre EVA e água fazendo com que o EVA adsorva água. Como consequência ocorre um enfraquecimento da zona de transição entre a pasta e o EVA.

Para o traço 1:6 nota-se, através da Tabela 8, um comportamento semelhante aos das argamassas com traço 1:3 em relação à resistência à compressão. Conforme aumenta a percentagem de EVA, na mistura, a resistência à compressão diminui. Aos 28 dias, esta redução foi de $35 \%$ para a argamassa produzida com $5 \%$ de substituição do agregado por EVA em relação à argamassa de referência. Nas argamassas EVA 1:6 10\% e EVA 1:6 $15 \%$ esta redução foi de $71 \%$ e $84 \%$, respectivamente. Comportamento que pode ser observado na Figura 7.

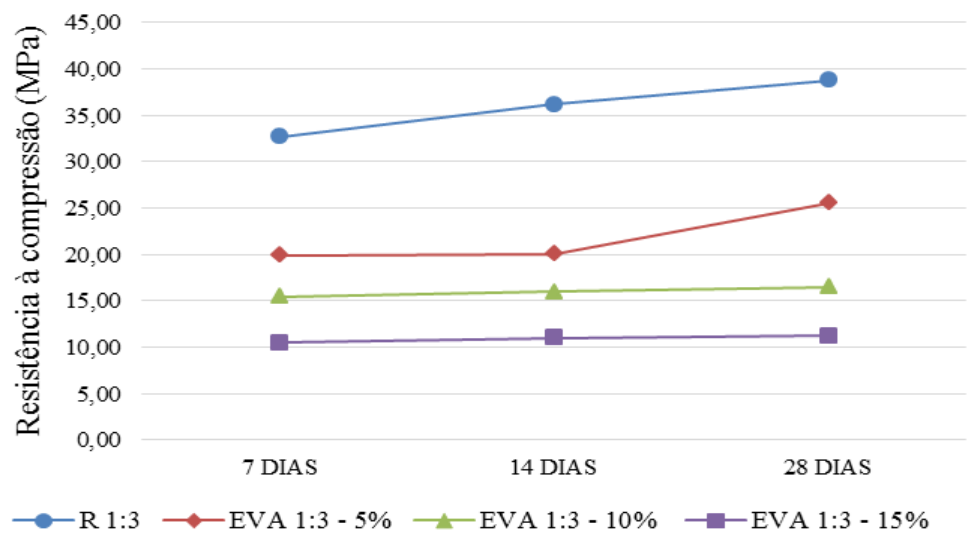

FIGURA 6: Resistência à compressão das argamassas com traço 1:3 aos 7, 14 e 28 dias.

FONTE: AUTOR (2016).

TABELA 8: Resistência à compressão (MPa) aos 7, 14 e 28 dias, das argamassas com traço 1:6.

\begin{tabular}{lccc}
\hline \multicolumn{4}{c}{ Resistência à compressão (MPa) aos 7 dias } \\
\hline Traço & \multicolumn{1}{c}{ Resistência Média } & DP & CV\% \\
\hline R 1:6 & 18,5 & 1,11 & 6 \\
EVA 1:6 5\% & 14,2 & 0,30 & 2 \\
EVA 1:6 10\% & 5,5 & 0,26 & 5 \\
EVA 1:6 15\% & 3,4 & 0,17 & 5 \\
\hline \multicolumn{4}{c}{ Resistência à compressão (MPa) aos 14 dias } \\
\hline Traço & Resistência Média & DP & CV\% \\
\hline R 1:6 & 19,0 & 1,39 \\
EVA 1:6 5\% & 14,6 & 0,73 & 7 \\
EVA 1:6 10\% & 5,7 & 0,12 & 5 \\
EVA 1:6 15\% & 3,5 & 0,17 & 2 \\
\hline \multicolumn{4}{c}{ Resistência à compressão (MPa) aos 28 dias } \\
\hline Traço & Resistência Média & DP \\
\hline R 1:6 & 23,4 & 1,24 & 5 \\
EVA 1:6 5\% & 15,2 & 0,70 & 5 \\
EVA 1:6 10\% & 6,8 & 0,47 & 5 \\
EVA 1:6 15\% & 3,7 & 0,20 & 7 \\
\hline
\end{tabular}




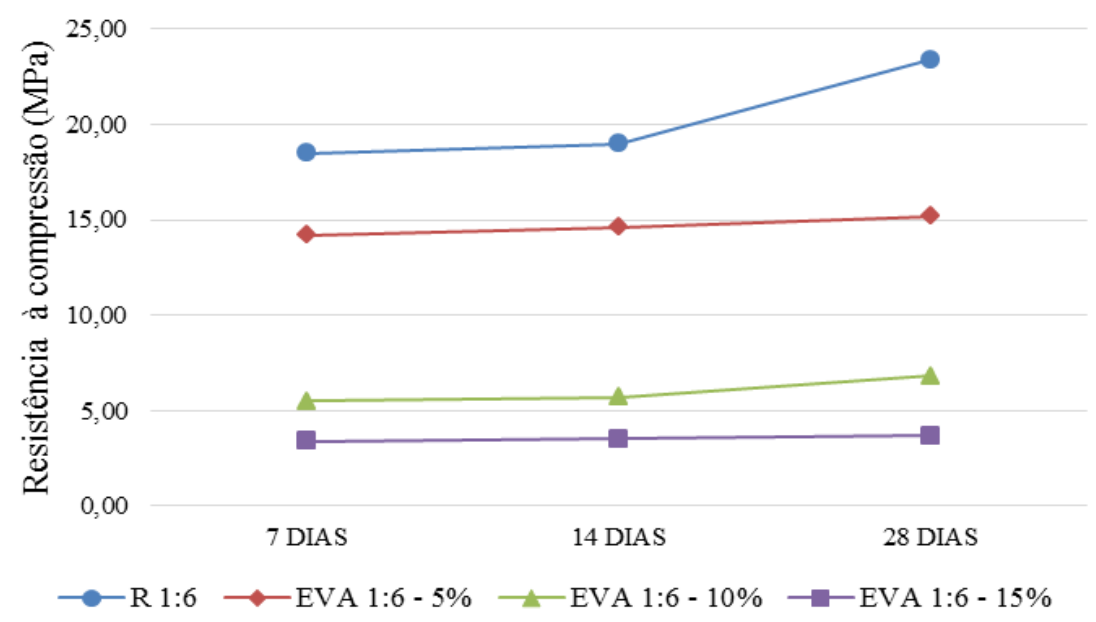

FIGURA 7: Resistência à compressão das argamassas com traço 1:6 aos 7, 14 e 28 dias.

FONTE: Autor (2016).

Em todas as misturas, as argamassas com traço 1:3 apresentaram resistência à compressão superiores as com traço 1:6, conforme mostra a Figura 8. Tal comportamento, já esperado, está associado ao maior teor de cimento Portland e menor a/c, nos traços 1:3. De forma geral, quanto maior o teor de substituição menor a resistência à compressão obtida. Comportamento similar foi observado por Garlet (1998) e Polari Filho (2005).
A NBR 13281 (ABNT, 2005) classifica as argamassas de revestimento em função da resistência à compressão conforme o Quadro 1.

Adotando a classificação da NBR 13281 (ABNT, 2005) e observando a Figura 8, percebe-se que a argamassa com menor resistência (EVA 1:6 15\%) apresenta uma resistência maior do que as argamassas tipo P1. Todas as demais têm resistência à compressão são superiores a $\mathrm{P} 4{ }^{8}$

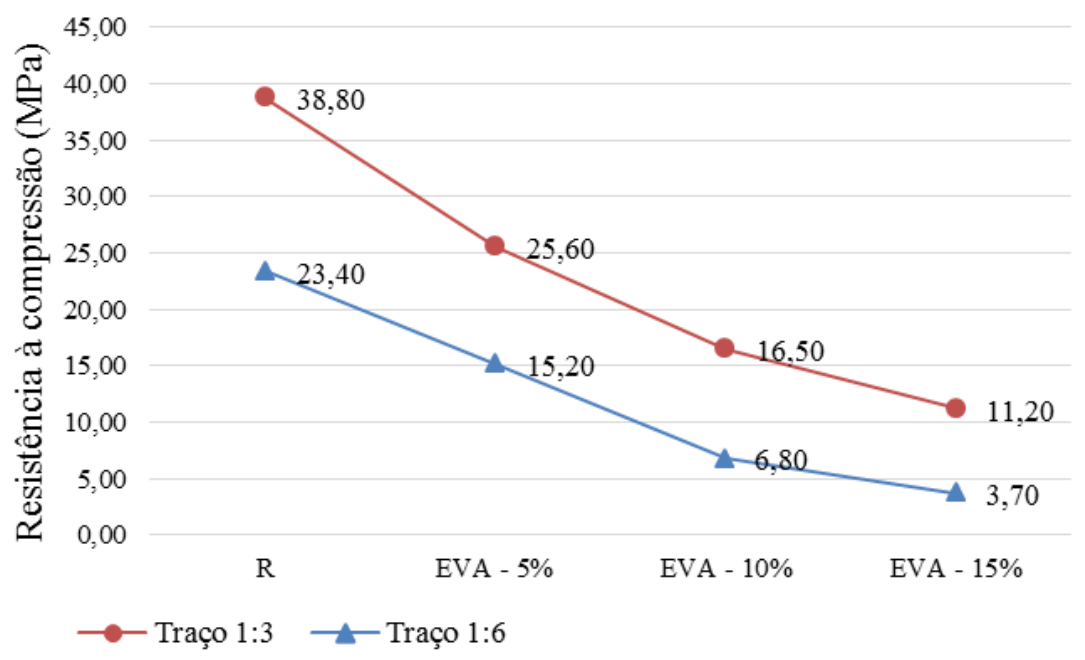

FIGURA 8: Resistência à compressão das argamassas com traço 1:3 e 1:6 aos 28 dias. FONTE: Autor (2016).

\footnotetext{
${ }^{8}$ Cabe destacar que essa classificação está adaptada a norma. Isso porque os ensaios de resistência realizados no trabalho foram de resistência à compressão axial, enquanto a classificação normativa é feita baseando-se na ruptura a compressão de corpos de prova cúbicos, provenientes de prismas ensaiados à tração na flexão.
} 


\begin{tabular}{|}
$\mid \begin{array}{c}\text { QUADRO 1: Classificação das argamassas quanto } \\
\text { à resistência à compressão. }\end{array}$ \\
\hline Classe & Resistência à compressão (MPa) \\
\hline P1 & $\leq 2,0$ \\
\hline P2 & 1,5 a 3,0 \\
\hline P3 & 2,5 a 4,5 \\
\hline P4 & 4,0 a 6,5 \\
\hline P5 & 5,5 a 9,0 \\
\hline P6 & $>8,0$ \\
\hline
\end{tabular}

FONTE: NBR 13281 (ABNT, 2005).

\subsubsection{Resistência à tração por compressão diametral}

Após realização do ensaio de absorção de água por capilaridade, as amostras foram submetidas ao ensaio de resistência à tração por compressão diametral. As Tabelas 9 e 10 apresentam as resistências à tração por compressão diametral dos corpos de prova ensaiados com base na NBR 7222 (ABNT, 1994).

\begin{tabular}{|c|c|c|c|}
\hline \multicolumn{4}{|c|}{$\begin{array}{l}\text { Resistência à tração por compressão diametral } \\
\text { (MPa) }\end{array}$} \\
\hline Traço & $\begin{array}{l}\text { Resistência } \\
\text { Média }\end{array}$ & DP & CV\% \\
\hline R 1:3 & 3,32 & 0,16 & 4,82 \\
\hline EVA $1: 35 \%$ & 2,28 & 0,29 & 12,72 \\
\hline EVA 1:3 10\% & 2,19 & 0,10 & 4,57 \\
\hline EVA 1:3 15\% & 1,62 & 0,12 & 7,41 \\
\hline
\end{tabular}

FONTE: Autor (2016).

Conforme apresentado na Tabela 9, as argamassas apresentaram uma perda de resistência à tração conforme o aumento do percentual de substituição do agregado por EVA aumenta. Para a argamassa com 5\% de substituição, a redução da resistência à tração foi de $31 \%$ em relação a argamassa de referência. Para os teores de $10 \%$ e $15 \%$ a redução na resistência à tração foi de $34 \%$ e $51 \%$, respectivamente.

Para o traço 1:6 nota-se, por meio da Tabela 10, um comportamento semelhante aos
TABELA 10: Resistência à tração por compressão diametral das argamassas com traço 1:6.

Resistência à tração por compressão diametral (MPa)

\begin{tabular}{lccc}
\hline \multicolumn{1}{c}{ Traço } & $\begin{array}{c}\text { Resistência } \\
\text { Média }\end{array}$ & DP & CV\% \\
\hline R 1:6 & 2,74 & 0,22 & 8,03 \\
EVA 1:6 5\% & 1,67 & 0,22 & 13,17 \\
EVA 1:6 10\% & 0,91 & 0,07 & 7,69 \\
EVA 1:6 15\% & 0,69 & 0,04 & 5,80 \\
\hline
\end{tabular}

das argamassas com traço 1:3 em relação à resistência à tração. Conforme aumenta a percentagem de EVA na mistura, a resistência à tração diminui. Para a argamassa produzida com $5 \%$ de substituição parcial do agregado por EVA esta redução foi de $39 \%$ em relação a argamassa de referência. Nas argamassas EVA 1:6 $10 \%$ e EVA 1:6 15\% a resistência à tração reduziu em torno de $67 \%$ e $75 \%$, respectivamente. Esse fenômeno pode ser explicado pela inserção de agregado menos resistente e que, provavelmente tem menor aderência com a pasta cimentícia do que a areia.

Ao avaliar o comportamento da resistência à tração por compressão diametral, percebe-se similaridades ao comportamento da resistência à compressão, ou seja, a inserção do agregado de EVA diminuiu a resistência à tração em argamassas. Outro fator analisado é a diminuição da resistência nas argamassas mais pobres (traço 1:6), as quais possuem um baixo teor de cimento e uma maior relação $a / c$, conforme mostrado na Figura 9.

A Figura 10 apresenta corpos de prova de argamassa de referência e de argamassa com agregado de EVA quando submetidos à resistência à tração por compressão diametral. Observa-se que a ruptura da argamassa com agregado de EVA não promove a separação dos grãos como ocorre nas argamassas de referência. Provavelmente, isso ocorreu porque os agregados de EVA são dúcteis, já os agregados naturais constituem-se materiais mais frágeis. 


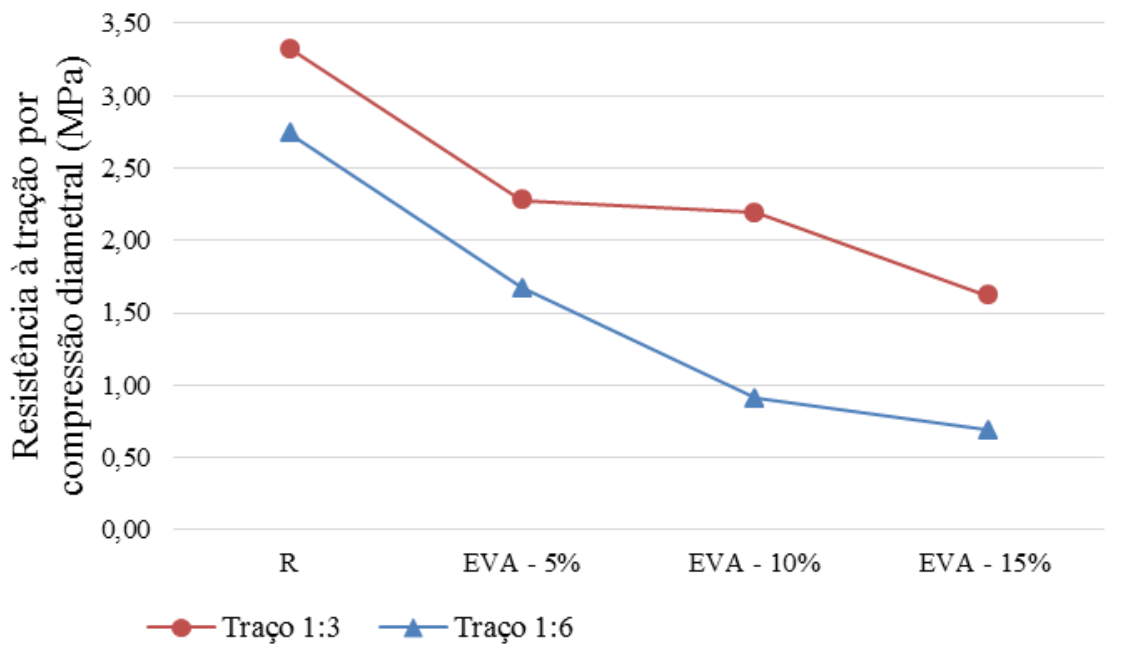

FIGURA 9: Resistência à tração por compressão diametral (MPa). FONTE: (AUTOR, 2016).
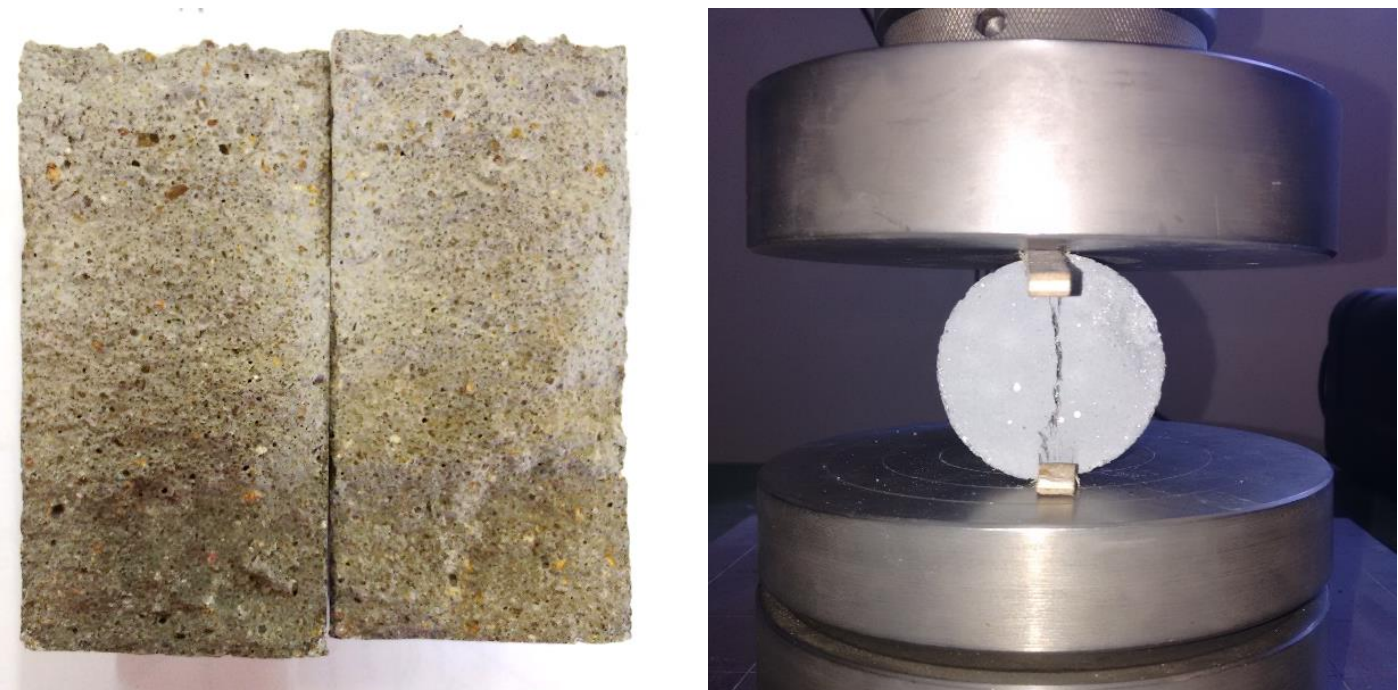

FIGURA 10: Corpos de prova submetidos à ensaio de resistência à tração por compressão diametral, à esquerda corpo de prova de referência e à direita corpo de prova com agregado de EVA. FONTE: (AUTOR, 2016).

\subsubsection{Absorção de água por imersão}

As Tabelas 11 e 12 apresentam os resultados da absorção de água por imersão das diferentes argamassas aos 28 dias.

TABELA 11: Absorção de água por imersão das argamassas traço $1: 3$ aos 28 dias.

Absorção de água por imersão (\%) aos 28 dias

\begin{tabular}{lccc}
\hline \multicolumn{1}{c}{ Traço } & $\begin{array}{c}\text { Absorção } \\
\text { Média }\end{array}$ & DP & CV\% \\
\hline R 1:3 & 5,94 & 0 & 0 \\
EVA 1:3 5\% & 4,35 & 0 & 0 \\
EVA 1:3 10\% & 4,07 & 0 & 0 \\
EVA 1:3 15\% & 3,24 & 0 & 0 \\
\hline & & \multicolumn{3}{c}{ FONTE: Autor (2016). }
\end{tabular}

Os dados apresentados na Tabela 11 mostram que a absorção de água por imersão é inversamente proporcional ao aumento de EVA nas misturas. Para a substituição de $5 \%$ de agregado por EVA, percebe-se uma redução de cerca $27 \%$ da absorção de água em relação a argamassas de referência. Já para substituições de $10 \%$ e 15\%, esta redução é de $31 \%$ e $45 \%$, respectivamente. Isso demonstra que a utilização de EVA em argamassa, melhora a redistribuição granulométrica, originando uma matriz menos porosa. Ao observar as curvas granulométricas do EVA e da areia (Figura 3) observa-se uma complementaridade granulométrica que reforça o entendimento de maior compacidade da matriz. 
Estes dados mostram que a adição de EVA, até certo limite, aumenta o grau de empacotamento das partículas, diminuindo a porosidade das argamassas, e aumenta sua estanqueidade.

Conforme é mostrado na Tabela 12 , nas argamassas com traço 1:6, para as substituições parciais de $5 \%$ e $10 \%$ do agregado por EVA, houve uma diminuição de $20 \%$ e $21 \%$, respectivamente, da absorção de água por imersão em relação à argamassa de referência. Porém, para a argamassa com substituição de $15 \%$ do agregado este comportamento mostrou-se diferente, ocorrendo um aumento de $95 \%$ da absorção.

Dos resultados apresentados na Figura 11 estima-se que a introdução de EVA nas argamassas, até um certo percentual, reduz os vazios resultantes do arranjo granulométrico mas, passando deste limite os vazios da argamassa são saturados e começam a formar novos vazios.

\section{TABELA 12: Absorção de água por imersão das} argamassas $1: 6$ aos 28 dias

\begin{tabular}{lccc}
\multicolumn{4}{c}{ Absorção de água por imersão (\%) aos 28 dias } \\
\hline Traço & $\begin{array}{c}\text { Absorção } \\
\text { Média }\end{array}$ & DP & CV\% \\
\hline R 1:6 & 5,40 & 0,00 & 0,00 \\
EVA 1:6 5\% & 4,30 & 0,00 & 0,00 \\
EVA1:6 10\% & 4,28 & 0,00 & 0,00 \\
EVA 1:6 15\% & 10,55 & 0,00 & 0,00 \\
\hline \multicolumn{4}{c}{ FONTE: Autor (2016). }
\end{tabular}

De forma geral, observa-se que quanto maior o teor de substituição de areia por EVA, menor é a absorção, exceto para o EVA1:6 15\%. Significa que as matrizes cimentícias geradas com EVA são menos porosas do que as de referências. Esses resultados parecem contraditórios aos resultados de resistência à compressão. Isso porque, geralmente, quanto mais compacta a matriz, maior a resistência à compressão. Todavia, é fácil compreender essa provável divergência quando se associa a resistência da matriz à resistência do agregado em EVA.

Segundo Oliveira et al (2000), a melhor compacidade de partículas ocorre quando os vazios deixados pelos grãos maiores são preenchidos pelos grãos menores. A inserção de novo material promove uma redistribuição granulométrica. Caso os grãos inseridos preencham os vazios deixados pelos agregados, há uma melhoria de compacidade e isso reflete na absorção. Entretanto, há um limite de preenchimento de vazios, ou seja, os vazios podem ser completamente preenchidos com 10\% de EVA. $A$ inserção de mais $5 \%$ promove uma redistribuição granulométrica originando mais vazios. Isso, provavelmente explica o aumento significativo de absorção para o traço EVA1:6 15\%.

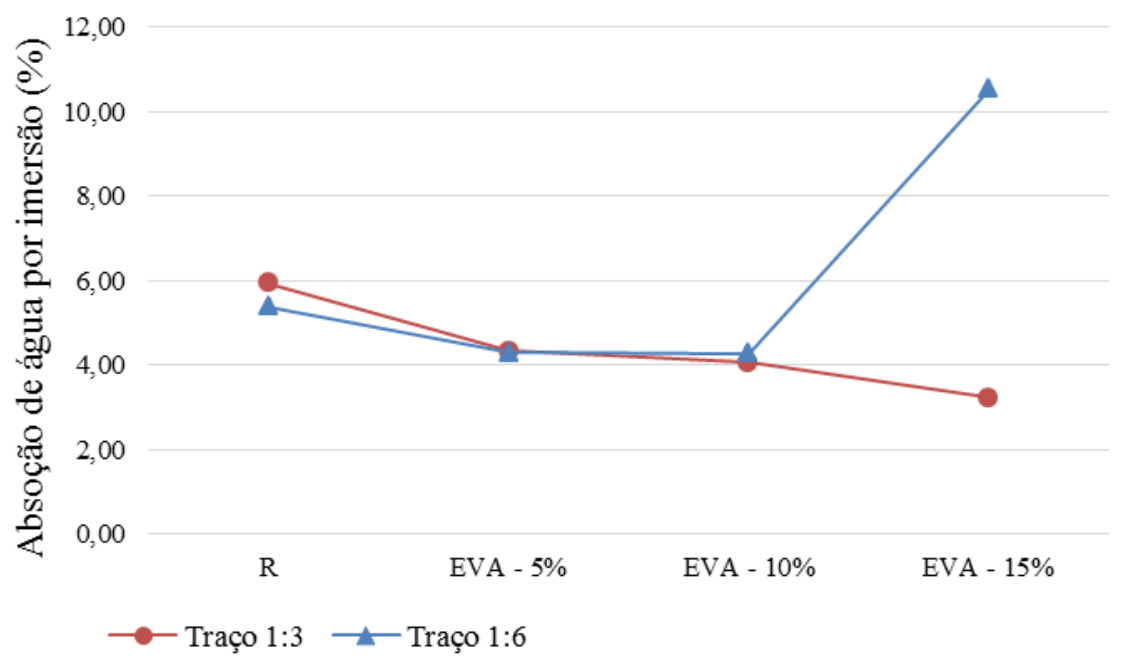

FIGURA 11: Absorção de água por imersão das argamassas aos 28 dias. FONTE: AUTOR (2016). 


\subsubsection{Absorção de água por capilaridade}

A absorção capilar nas argamassas é normatizada pela NBR 9779 (ABNT, 2012), que determina a massa de água absorvida em função da área de contato do corpo de prova. O fenômeno de absorção capilar depende da viscosidade, densidade e tensão superficial do líquido e acontece em estruturas porosas devido a força de atração dos poros sobre os líquidos que estão em contato com a superfície. A absorção capilar, bem como as condições do substrato, tem importante influência sobre o comportamento das argamassas, como por exemplo, a transferência de líquido entre o revestimento e o substrato e as resistência de aderência e ao cisalhamento entre os mesmos (ARAÚJO JR, 2004).

As Tabelas 13 e 14 apresentam os resultados da absorção de água por capilaridade das diferentes argamassas aos 28 dias.

TABELA 13: Absorção de água por capilaridade das argamassas com traço 1:3 aos 28 dias.

Absorção de água por capilaridade $\left(\mathrm{g} / \mathrm{cm}^{2}\right)$ aos 28 dias

\begin{tabular}{lclc}
\hline Traço & $\begin{array}{c}\text { Absorção } \\
\text { Média }\end{array}$ & DP & CV\% \\
\hline R 1:3 & 0,67 & 0,01 & 1,49 \\
EVA 1:3 5\% & 0,46 & 0,01 & 2,17 \\
EVA 1:3 10\% & 0,35 & 0,02 & 5,71 \\
EVA 1:3 15\% & 0,29 & 0,02 & 6,90 \\
\hline & & \multicolumn{2}{c}{ FONTE: Autor (2016). }
\end{tabular}

Os dados apresentados na Tabela 13 mostram que a absorção de água por capilaridade é inversamente proporcional ao aumento de EVA nas misturas. Para a substituição de $5 \%$ de agregado por EVA, percebe-se uma redução de $31 \%$ da absorção de água em relação a argamassas de referência. Já para substituições de 10\% e 15\%, esta redução é de $48 \%$ e $57 \%$, respectivamente.

Conforme é mostrado na Tabela 14, nas argamassas com traço 1:6, para as substituições parciais de $5 \%$ e $10 \%$ do agregado por EVA, houve uma diminuição de $27,54 \%$ e 52,17\%, respectivamente, da absorção de água por capilaridade em relação a argamassa de referência. Porém, para a argamassa com substituição de $15 \%$ do agregado esta redução foi de 2,90\% de absorção de água por capilaridade em relação ao referencial.

TABELA 14: Absorção de água por capilaridade das argamassas com traço 1:6 aos 28 dias.

Absorção de água por capilaridade $\left(\mathrm{g} / \mathrm{cm}^{2}\right)$ aos 28 dias

\begin{tabular}{lccr}
\hline Traço & $\begin{array}{c}\text { Absorção } \\
\text { Média }\end{array}$ & DP & CV\% \\
\hline R 1:6 & 0,69 & 0,03 & 4,35 \\
EVA 1:6 5\% & 0,50 & 0,02 & 4,00 \\
EVA 1:6 10\% & 0,33 & 0,03 & 9,09 \\
EVA 1:6 15\% & 0,67 & 0,03 & 4,48 \\
\hline & & FONTE: Autor (2016).
\end{tabular}



FIGURA 12: Absorção de água por capilaridade das argamassas aos 28 dias. FONTE: Autor, 2016. 
No ensaio de absorção de água capilar, os corpos de prova apresentaram características de absorção semelhante às apresentadas nos ensaios de absorção por imersão, conforme apresentado na Figura 12. O aumento dos teores de EVA na mistura, com exceção das argamassas EVA 1:6 $15 \%$, preenche os espaços vazios deixados pelo agregado natural e que não foram preenchidos pela pasta de cimento e diminui a absorção de água.

Cabe destacar que se há redução de absorção por capilaridade, há diminuição da formação de poros intercomunicáveis na argamassa, exceto para EVA1:6 15\%. Esta singularidade já foi discutida previamente e cabe mesma interpretação. É importante destacar que quanto menor a absorção capilar, maior a estanqueidade da argamassa de revestimento, por exemplo, e maior a proteção da edificação aos agentes agressivos do ambiente. Portanto, a inserção de EVA, melhora o desempenho das argamassas no critério estanqueidade, exceto EVA1:6 15\%.

\section{CONCLUSÕES}

Após análise dos resultados da parte experimental pode-se concluir que:

- Quanto maior o teor de substituição do agregado miúdo por EVA, menores as resistências mecânicas (compressão e tração) das argamassas estudadas.

- Mesmo reduzindo as resistências, apenas o traço EVA 1:6 15\% apresentou resistência à compressão inferior ao tipo P4, classificado pela NBR 13281 (ABNT, 2005). Fato que demonstra a viabilidade do emprego do resíduo em argamassas que exigem desempenho mecânico classificado nas classes desta norma.

- A argamassa com resíduo de EVA diminuiu, de forma geral, a absorção por imersão e por capilaridade. Melhorando o desempenho destas no requisito estanqueidade.

Desta forma pode-se concluir que a produção de argamassas utilizando EVA em substituição ao agregado natural é viável, todavia é necessário avaliar os parâmetros mínimos de aplicação para cada finalidade. Para argamassas de revestimento, por exemplo, é necessário avaliar a aderência, sem a qual o revestimento não atenderá a nenhuma de suas funções.

\section{AGRADECIMENTOS}

Registra-se o agradecimento à Empresa Dass Calçados pelo apoio dado a todas as etapas da pesquisa.

\section{REFERÊNCIAS BIBLIOGRÁFICAS}

ALVARENGA, Rita de Cássia Silva Sant'anna et al. Avaliação de ensaios em argamassas para uso em pisos e revestimentos: Análise comparativa entre as normas. Construindo, Belo Horizonte, v. 5, n. 1, p.16-23, 2013. Semestral. Disponível em: $<$ http://www.fumec.br/revistas/construindo/article/do wnload/1663/1216>.

ANDRADE, Lucimara Aparecida Schambeck; MEDEIROS, Rennan. Reaproveitamento de rejeitos de EVA para produção de placas utilizáveis na construção civil. Revista Científica Indexada Linkania Master, Tubarão, v. 3, n. 3, p.1-13, jul. 2012. Trimestral.

ARAÚJO JR., J.M. Contribuição ao Estudo das propriedades Físico-Mecânicas das Argamassas de Revestimento. Dissertação (Mestrado em Estruturas e Construção Civil) - Programa de pós-graduação em Estrutura e Construção Civil, Universidade de Brasília, 2004, 175p.

ASSOCIAÇÃO BRASILEIRA DAS INDÚSTRIAS DE CALÇADOS (ABICALÇADOS). Sem fronteiras. Disponível em: < http://www.abicalcados.com.br/midia/modulodownload/arquivos/14556257909322.pdf>. Acesso em: 20 fev. 2016.

ASSOCIAÇÃO BRASILEIRA DE CIMENTO PORTLAND. Guia básico de utilização do cimento Portland. 7.ed. 28p. (BT-106). São Paulo, 2002.

ASSOCIAÇÃO BRASILEIRA DE NORMAS TÉCNICAS. Agregados para concretos - Especificação. NBR 7211: Rio de Janeiro, 1996.

Cimento Portland-Determinação da resistência à compressão. NBR 7215: Rio de Janeiro, 1996. 
Concreto e argamassa - Determinação da resistência à tração por compressão diametral de corpos de prova cilíndricos. NBR 7222: Rio de Janeiro, 2011.

Argamassa e concreto endurecidos Determinação da absorção de água por imersão Índice de vazios e massa específica. NBR 9778: Rio de Janeiro, 2005.

Argamassas e concretos endurecidos Determinação da absorção de água por capilaridade. NBR 9779: Rio de Janeiro, 2012.

Argamassa para assentamento e revestimento de paredes e tetos - Determinação da densidade de massa e do teor de ar incorporado. NBR 13278: Rio de Janeiro, 2005.

Argamassa para assentamento e revestimento de paredes e tetos - Requisitos. NBR 13281: Rio de Janeiro, 2005.

Edificações habitacionais - Desempenho. NBR

15575: Rio de Janeiro, 2013.

Agregado miúdo - Determinação da massa específica e massa aparente. NBR NM 52: Rio de Janeiro, 2009.

Agregados - Determinação da composição granulométrica. NBR NM 284: Rio de Janeiro, 2003.

BALDIN, Nelma; ORTH, Cíntia Madureira; ZANOTELLI, Cladir Teresinha. A geração de resíduos sólidos em um processo produtivo de uma indústria automobilística: uma contribuição para a redução. Gestão \& Produção, São Carlos, v. 21, n. 2, June 2014. Disponível em: $<$ http://www.scielo.br/scielo.php?script=sci_arttext\&pi $d=S 0104-530 \times 2014000200016 \&$ lang=pt>.

BRINGEL, R. M.; SOARES, S. A.; SOARES, J. B. Propriedades químicas e reológicas de asfalto modificado por copolímero EVA. In.: $3^{\circ}$ Congresso Brasileiro de P\&D em Petróleo e Gás. Instituto Brasileiro de Petróleo e Gás - IBP - Salvador, 2005. 6 p. Disponível em:

$<$ http://www.portalabpg.org.br/PDPetro/3/trabalhos/IB P0605_05.pdf>.

CARASEK, Helena. Argamassas. In: IBRACON (Org.). Materiais de construção civil e princípios de ciência e engenharia dos materiais. São Paulo: Geraldo C. Isaia, 2010.
CARDOSO, Fábio Alonso. Método de formulação de argamassa de revestimento baseado em distribuição granulométrica e comportamento reológico. 2009. 138 f. Tese (Doutorado) - Curso de Engenharia Civil, Departamento de Engenharia de Construção Civil, Universidade de São Paulo, São Paulo, 2009. Disponível em:

<http://www.teses.usp.br/teses/disponiveis/3/3146/tde21122009-125012/pt-br.php>.

DEBAPRIYA, D.; SUKUMAR, M.; ADHIKARI, B. Reclaiming of rubber by a Renewable Resource Material (RRM). II. Comparative Evaluation of Reclaiming Process of NR Vulcanizate by RRM and diallyl disulfide. Journal of Applied Polymer Science, v.73, p.2951, 1999.

DUBAJ, Eduardo. Estudo comparativo entre traços de argamassa de revestimento utilizadas em Porto Alegre. Universidade Federal do Rio Grande do Sul. Dissertação de mestrado. Porto Alegre, 2000, 102p.

GARLET, Givanildo. Aproveitamento de resíduo de E.V.A. (Ethylene Vinyl Acetate) como agregado para concreto leve na construção civil. 1998. $146 \mathrm{f}$. Dissertação (Mestrado) - Curso de Pós-graduação em Engenharia Civil, Escola de Engenharia, Universidade Federal do Rio Grande do Sul, Porto Alegre, 1998.

LA SERNA, Humberto Almeida de; REZENDE, Mácio Marques. Agregados para construção civil. DNPM Economia Mineral do Brasil, ANEPAC, São Paulo, 2009. Disponível em: <http://anepac.org.br/wp/wpcontent/uploads/2011/07/DNPM2009.pdf>.

LODI, Victor Hugo. Viabilidade técnica e econômica do uso de areia de britagem em concretos de cimento portland na região de Chapecó - SC. Dissertação (PósGraduação) - Universidade Federal de Santa Catarina convênio Unochapecó, Programa de Pós-Graduação em Engenharia Civil, Florianópolis, 2006. Disponível em: $<$ http://www.basalto.eng.br/dissertacao_vhl_vs_final.p $d f>$.

MARQUES, M. A. et al. Análise através de de imagens de raio-x da incorporação de resíduos de EVA em Cimento Portland. In: 56 @ CONGRESSO BRASILEIRO DE CERÂMICA, 1ㅇ CONGRESSO LATINO-AMERICANO DE CERÂMICA E IX BRASILIAN SYMPOSIUN ON GLASS AND RELATED MATERIALS, 2012, Curitiba. Anais. Curitiba: Associação Brasileira de Cerâmica, 2012. p. 2227 - 2238. 
MELO, Aluísio Braz; LIMA FILHO, Marçal Rosas Florentino. Avaliação de desempenho estrutural de protótipos com paredes construídas com blocos EVA. Ambiente Construído, Porto Alegre, v. 9, n. 4, p.141-155, out. 2009. Trimestral.

MENEZES, R. R., NEVES, G. A., FERREIRA, H. C. 0 estado da arte sobre o uso de resíduos como matérias-primas cerâmicas alternativas. Revista Brasileira de Engenharia Agrícola e Ambiental, v. 6, n. 2, p. 303-317, 2002a.

MENEZES, R. R. et al. Recycling of granite industry waste from the northeast region of Brazil. Environmental Management and Health, v. 13, p. 134$142,2002 b$.

MENEZES, R. R. et al. Use of granite sawing wastes in the production of ceramic bricks and tiles. Journal of the European Ceramic Society, v. 25, p. 1149-1163, 2005.

OLIVEIRA, Ivone R. de et al. Dispersão e empacotamento de partículas: princípios e aplicações em processamento cerâmico. São Paulo: Fazendo Arte Editorial, 2000.

POLARI FILHO, Rômulo Soares. Contribuição ao processo de reciclagem dos resíduos da indústria de calçados na construção civil: Bloco EVA - Uma alternativa às alvenarias das construções.2005. $90 \mathrm{f}$. Dissertação (Mestrado) - Curso de Programa de Pósgraduação em Engenharia Urbana, Centro de Tecnologia, Universidade Federal da Paraíba, João Pessoa, 2005.

ROCHA, Aretuza K. A. da et al. Argamassas mistas para alvenaria utilizando resíduo de caulim - Parte I: comportamento mecânico. Revista Escola de Minas, Ouro Preto, v. 61, n. 4, p.505-512, out. 2008. Bimestral. Disponível em: <http://www.scielo.br/pdf/rem/v61n4/v61n4a16.pdf>.

ROCHA, Fabiano de Melo Duarte. Aproveitamento de resíduos sólidos industriais em materiais alternativos na perspectiva da construção seca: Bloco EVA Intertravamento e racionalização das alvenarias. 2008. 105 f. Dissertação (Mestrado) - Curso de Pós-graduação em Engenharia Urbana, Centro de Tecnologia, Universidade Federal da Paraíba, João Pessoa, 2008.
SANTIAGO, Edila Quinteiro Ribeiro. Utilização de agregados de EVA e RCD para a obtenção de concretos leves. 2008. 185 f. Dissertação (Mestrado) - Curso de Programa de Pós-graduação em Engenharia Civil e Ambiental, Departamento de Tecnologia, Universidade Estadual de Feira de Santana, Feira de Santana, 2008.

SANTIAGO, E. Q. R. et al. Mechanical behavior of recycled lightweight concrete using EVA waste and CDW under moderate temperature. Ibracon Structures And Materials Journal, São Paulo, v. 2, n. 3, p.211-221, set. 2009. Disponível em: <http://www.scielo.br/scielo.php?script=sci_arttext\&pi $d=$ S1983-41952009000300001>. 